\title{
PIPERINE IN THE PREVENTION OF THE DECREASED TAMOXIFEN SENSITIVITY IN MCF-7 BREAST CANCER CELL LINE
}

\author{
SANDY VITRIA KURNIAWAN ${ }^{1,2}$, LIES SUGIARTI ${ }^{1}$, SEPTELIA INAWATI WANANDI ${ }^{3}$, MELVA LOUISA $^{4 *}$ \\ ${ }^{1}$ Biomedical Sciences Postgraduate Program, Faculty of Medicine, Universitas Indonesia, Jakarta 10430, Indonesia. ${ }^{2}$ Department of \\ Pharmacology and Pharmacy, Faculty of Medicine, Atma Jaya Catholic University, Jakarta 12930, Indonesia. ${ }^{3}$ Department of Biochemistry \\ and Molecular Biology, Faculty of Medicine, Universitas Indonesia, Jakarta 10430, Indonesia. ${ }^{4}$ Department of Pharmacology and \\ Therapeutics, Faculty of Medicine, Universitas Indonesia, Jakarta 10430, Indonesia. Email: melva.louisa@gmail.com
}

Received: 18 July 2018, Revised and Accepted: 19 November 2018

\section{ABSTRACT}

Objective: This study was designed to analyze the role of piperine in modulating P-glycoprotein mRNA expression when added in combination with tamoxifen to breast cancer cells in culture.

Methods: MCF- 7 breast cancer cells were treated with $1 \mu \mathrm{M}$ tamoxifen with or without piperine $(12.5,25$, or $50 \mu \mathrm{M})$ or verapamil $50 \mu \mathrm{M}$ (P-glycoprotein inhibitor positive control) for up to 12 days. We assessed the cell viability and isolated total RNA from them. We quantified P-glycoprotein expressions using quantitative reverse transcription polymerase chain reaction.

Results: Administration of various doses of piperine decreased MCF-7 breast cancer cell viability. Piperine, when given in combination with tamoxifen, decreased the expression of P-glycoprotein mRNA in cells compared with the expression in cells treated with tamoxifen only. The effects were shown to be dose dependent.

Conclusion: Piperine prevents the development of breast cancer cell tamoxifen resistance, probably through its inhibition of P-glycoprotein expression.

Keywords: P-glycoprotein, Piperine, Tamoxifen.

(c) 2018 The Authors. Published by Innovare Academic Sciences Pvt Ltd. This is an open access article under the CC BY license (http://creativecommons. org/licenses/by/4. 0/) DOI: http://dx.doi.org/10.22159/ijap.2018.v10s1.74

\section{INTRODUCTION}

Breast cancer continues to be a global burden for women as the most common cancer and the leading cause of cancer deaths in women [1]. Premenopausal women with estrogen-positive type of breast cancer can benefit from tamoxifen treatment [2]. However, studies have shown that the response rates to tamoxifen are approximately $17-33 \%$ with times to progression between 5 and 8.3 months $[3,4]$. The long-term use of tamoxifen has been shown to induce decreased cancer cell sensitivity to the drug; one mechanism of resistance is the increased expression of drug efflux transporters such as P-glycoprotein [5].

The P-glycoprotein efflux transporter is part of the superfamily of ATPbinding cassette transporters. P-glycoprotein mediates resistance to various anticancer drugs, such as tamoxifen, vincristine, vinblastine, and paclitaxel. The long-term use of anticancer drugs can trigger increased P-glycoprotein expression through the activation of pregnane $\mathrm{X}$ receptor (PXR) so that the anticancer drugs cannot attain effective concentrations inside the cells, leading to drug treatment failure [6].

Various efforts have been devised to overcome this resistance; one of them is to provide P-glycoprotein inhibitors in addition to chemotherapy. Three generations (1, 2, and 3) of P-glycoprotein inhibitors have been developed. However, the preclinical trials done on these drugs have not been satisfactory. The clinical applications for P-glycoprotein inhibitors are still limited and more research is needed to ensure the deployment of a safe and effective P-glycoprotein inhibitor $[7,8]$.

One alternative source of P-glycoprotein modulators is found in plants. Some drugs of natural origin have beneficial effects, such as anticancer effects and also as inhibitors of P-glycoprotein [9]. Piperine is one of the known natural isolates inhibiting P-glycoprotein. It is an alkaloid found in Piper longum L. and Piper nigrum L. plants, better known as black pepper [10]. Piperine helps to reduce inflammation, improves digestive function, reduces pain and asthma, increases the production of serotonin, reduces gastric ulceration, and displays antitumor activity [11]; therefore, it is expected to provide dual benefits for the management of breast cancer.

In this study, we aimed to analyze the role of piperine in modulating P-glycoprotein mRNA expression when treating breast cancer cell in combination with tamoxifen.

\section{METHODS}

Reagents and equipment

We conducted an in vitro study using MCF-7 breast cancer cells. The breast cancer cell line MCF-7 was obtained from the Makmal Laboratory (FKUI, Indonesia). Tamoxifen was obtained from Santa Cruz (USA). Piperine, verapamil, and dimethylsulfoxide (DMSO) were obtained from Sigma-Aldrich. Dulbecco's minimal essential medium (DMEM), triple express, and fetal bovine serum (FBS) were obtained from Gibco (Singapore). The Total RNA Mini Kit was obtained from Geneaid (Taiwan). Primers used for quantitative reverse transcription polymerase chain reaction (qRT-PCR) were purchased from $1^{\text {st }}$ base (Singapore). The KAPA SYBR fast one-step RT-PCR Kit Bio-Rad iCycler was obtained from KAPA Biosystems (USA). All other chemicals used in this study were of the highest commercially available purity.

\section{Cell culture}

MCF-7 cells were cultured on DMEM medium supplemented with 10\% FBS, penicillin $100 \mathrm{IU} / \mathrm{mL}$, streptomycin $100 \mu \mathrm{g} / \mathrm{mL}$, and fungizone $2.5 \mu \mathrm{g} / \mathrm{mL}$ at $37{ }^{\circ} \mathrm{C}$ and $5 \% \mathrm{CO}_{2}$. We subcultured the cells at about $80-$ $90 \%$ confluency and placed them onto 6-well plates for drug treatments. 
Preparation of drugs

Tamoxifen, verapamil, and piperine were dissolved in DMSO and then diluted into DMEM at the desired concentrations. The final DMSO concentrations were $<0.001 \%$. We used a concentration of tamoxifen of $1 \mu \mathrm{M}$, based on a publication using MCF-7 cells [12].

\section{Drug treatment}

We plated 100,000 MCF-7 cells onto a 6-well plate and incubated them for $24 \mathrm{~h}$ before the drug treatment. Tamoxifen $(1 \mu \mathrm{M})$ and piperine $(12.5,25$ and $50 \mu \mathrm{M})$ were applied together in the exchange media on days $1,4,6,9$, and 12 . We used DMSO (0.001\%) for our negative control and verapamil $(50 \mu \mathrm{M})$ for the positive control with a P-glycoprotein inhibitor. At the end of each time point, we harvested the cells using triple express and counted them using a hemocytometer. Next, we performed total RNA extractions according to the manufacturers' procedure.

\section{qRT-PCR}

Quantitative RT-PCRs were done on a Bio-Rad iCycler machine using the KAPA SYBR Fast one-step qRT-PCR kit (KAPA, USA). We used primer sequences to amplify the P-glycoprotein gene and the GAPDH gene as a reference. The primer sequences used were: GAPDH Fwd: 5'-GTTGCTGTAGCCAAATTCGTTGT-3', GAPDH Rev: 5'-GGTGGTCTCCTCTGACTTCAACA-3', P-glycoprotein Fwd: 5'-AATAG ATGCC TTTCTGTGCAAG-3', and P-glycoprotein Rev: 5'-AAAGCGACT GAATGTTCAGTGG-3'. Samples were prepared by mixing $200 \mathrm{nM}$ of each primer, 7.5 $\mu \mathrm{L}$ KAPA SYBR Fast qPCR Master Mix Green, 0.4 mL KAPA RT Mix (50X), $0.4 \mathrm{~mL}$ dUTP, $275 \mathrm{ng}$ RNA Template, and RNase-free water to $15 \mu \mathrm{L}$. The samples were incubated in the qRT-PCR machine under the following conditions: $5 \mathrm{~min}$ at $42^{\circ} \mathrm{C}$ for cDNA synthesis, $5 \mathrm{~min}$ at $95^{\circ} \mathrm{C}$ for reverse transcriptase inactivation, and 35 cycles consisting of $3 \mathrm{~s}$ at $95^{\circ} \mathrm{C}$ for template denaturation and $1 \mathrm{~min}$ at $64^{\circ} \mathrm{C}$ for primer annealing, plus $30 \mathrm{~s}$ for the extension phase. After that, a final elongation for $5 \mathrm{~min}$ and $30 \mathrm{~s}$ was added to the cycle 81 times for obtaining melting curves. The Thermal Cycler software calculated the threshold value (Ct) automatically. The data were then processed according to the Ct Livak method [13].

\section{RESULTS}

Treatment with tamoxifen $(1 \mu \mathrm{M})$ suppressed the viability of MCF7 cells for up to 4 days. However, after 6 days of treatment, we found that the cell growth increased compared with that in the control (Fig. 1).

The analysis of P-glycoprotein mRNA expressions after treatment of MCF-7 cells with tamoxifen $(1 \mu \mathrm{M})$ showed a similar trend to that in the cell viability curve, increasing in a time-dependent manner starting on day 6 (Fig. 2).

The concomitant treatment with tamoxifen $(1 \mu \mathrm{M})$ and piperine (12.5, 25 , or $50 \mu \mathrm{M}$ ) reduced the number of viable MCF-7 cells in dose- and time-dependent manners (Fig. 3)

We found decreased P-glycoprotein mRNA expressions after the concomitant treatment of MCF-7 cells with tamoxifen $(1 \mu \mathrm{M})$ and either piperine $(12.5,25$, and $50 \mu \mathrm{M})$ or verapamil $(50 \mu \mathrm{M})$ (Fig. 4). The greatest decrease in P-glycoprotein expression was observed with $50 \mu \mathrm{M}$ of verapamil.

\section{DISCUSSION}

We conducted this study to investigate the role of piperine, when given in combination with tamoxifen, in the prevention of breast cancer cells' resistance to tamoxifen. Our results showed that piperine successfully increased the efficacy of tamoxifen on the elimination of breast cancer cells along with a decrease in P-glycoprotein expression.

We showed that exposure to $1 \mu \mathrm{M}$ tamoxifen can suppress the growth of MCF-7 cells during the early days, but after 6 days, tamoxifen fails to suppress the growth of breast cancer cells, as the expression of

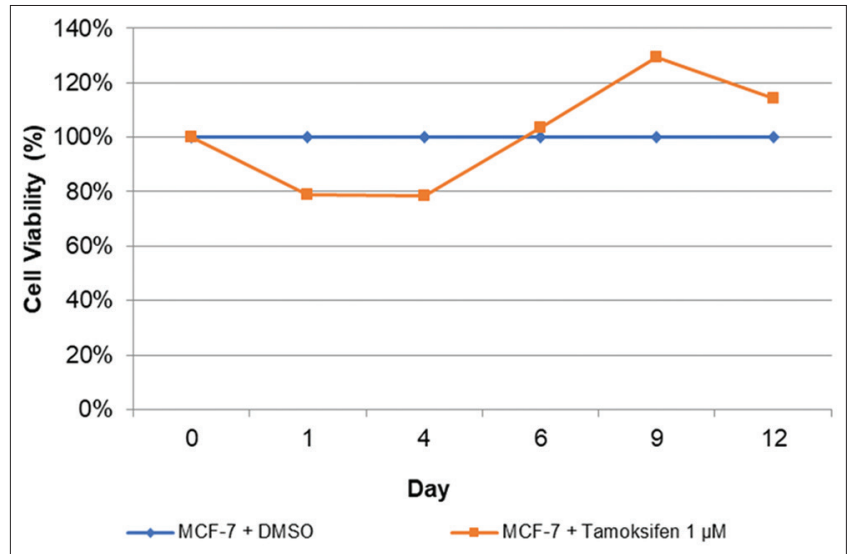

Fig. 1: Percentage viability of MCF-7 cells after exposure to $1 \mu \mathrm{M}$ tamoxifen for 12 days

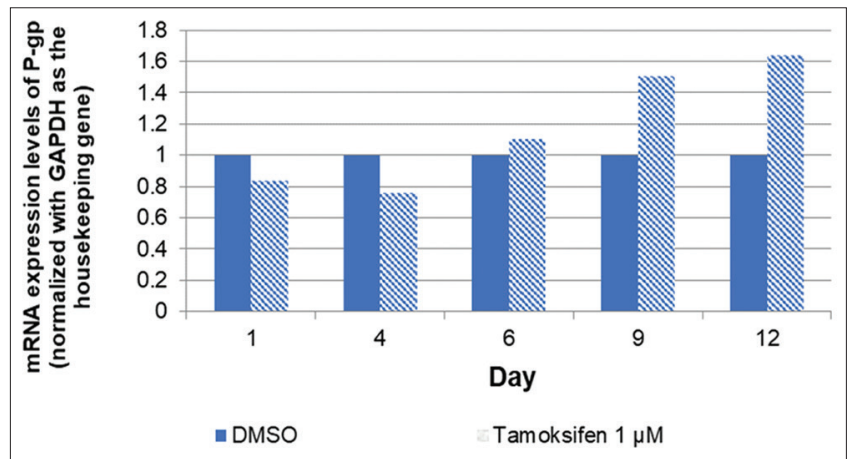

Fig. 2: Levels of P-glycoprotein mRNA expressions (normalized to GAPDH as housekeeping gene) in MCF-7 breast cancer cells after treatment with $1 \mu \mathrm{M}$ tamoxifen for up to 12 days

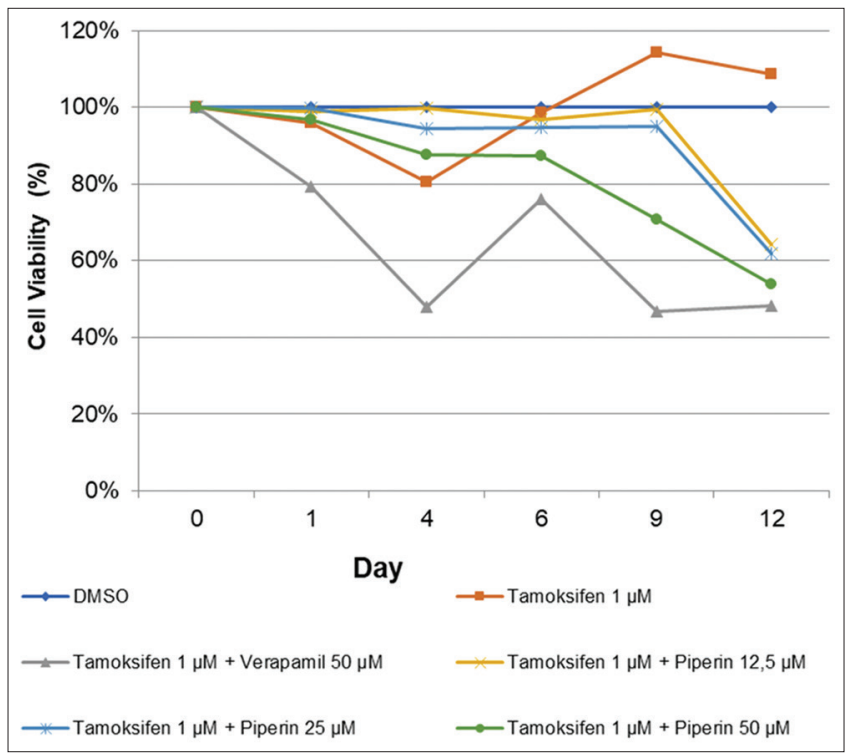

Fig. 3: Percentage of cell viability of MCF-7 breast cancer cells after concomitant treatment of tamoxifen $1 \mu \mathrm{M}$ with piperine $(12.5,25$, and $50 \mu \mathrm{M})$ or with verapamil $(50 \mu \mathrm{M})$

P-glycoprotein increases. This dose-dependent mechanism of increased mRNA expression of P-glycoprotein has been shown in human hepatocyte primary cells treated with tamoxifen $(1,2,5$, or $5 \mu \mathrm{M}$ for 72 h) [14]. 


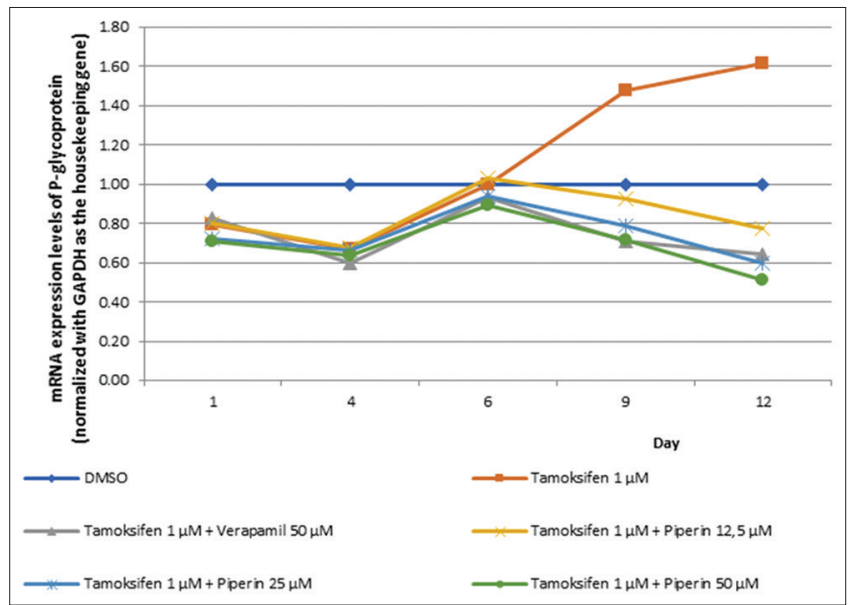

Fig. 4: Levels of P-glycoprotein mRNA expressions in MCF-7 cells after concomitant treatment of tamoxifen $(1 \mu \mathrm{M})$ with piperine $(12.5,25$, and $50 \mu \mathrm{M})$ or with verapamil $(50 \mu \mathrm{M})$

Another study using tamoxifen $(10 \mu \mathrm{M})$ for $48 \mathrm{~h}$ to induce an increase in the mRNA expression of P-glycoprotein in human colon adenocarcinoma cells showed an increase in that mRNA expression associated with the activation of PXR [6]. The differences in the dose and exposure duration to tamoxifen treatment used in different studies show that these variables are associated to the onset of an increase in the mRNA expression of P-glycoprotein.

As mentioned, tamoxifen can activate PXR, which forms a heterodimer with the retinoid $\mathrm{X}$ receptor and binds the DR-4 response element, a functional promoter for the P-glycoprotein gene, resulting in an increase in the P-glycoprotein expression [6,15,16-19].

However, some studies have shown that tamoxifen may also act as a P-glycoprotein inhibitor $[8,17,14]$. This is in contrast with our results as well as those of other groups. But, it is possible that, at high concentrations, tamoxifen inhibits P-glycoprotein as a competitive inhibitor of the pump itself. Tamoxifen, which is a P-glycoprotein substrate, would compete with other substrates by saturating the pump's binding sites at high enough concentrations and would increase the buildup of substrates inside the cell, effectively inhibiting the pump's function $[14,20]$.

In this study, we found that the administration of piperine at various concentrations can prevent increased P-glycoprotein mRNA expressions in a dose-dependent manner over time. The trend of the curve in Fig. 4 coincides with the one for the growth curves of MCF-7 cells after the administration of piperine at various concentrations as shown in Fig. 3.

Our result is consistent with the finding that piperine at $12.5,25$, and $50 \mu \mathrm{M}$ for $48 \mathrm{~h}$ helps overcome the resistance of MCF-7 cells to doxorubicin [21].

In addition, piperine at doses between 1 and $250 \mu \mathrm{M}$ can inhibit the P-glycoprotein efflux of digoxin and cyclosporine A in Caco-2 cells with $\mathrm{IC}_{50}$ values of 15.5 and $74.1 \mu \mathrm{M}[22]$.

Conversely, piperine has been shown to exert its effects on the P-glycoprotein in a concentration-dependent manner; at small concentrations, piperine can inhibit P-glycoprotein, but at greater concentrations (50 and $100 \mu \mathrm{M}$ ), piperine can induce P-glycoprotein [23].

In our study, the effects of treatment with piperine plus tamoxifen on the mRNA expression and cell viability of the MCF-7 cells began being apparent after day 6 (when the decreased sensitivity of the cells started to develop). This suggests that the administration of piperine from the beginning may not be required. However, further studies are required to confirm this result.

In this regard, it would be important to detect the beginning of the increased P-glycoprotein expression in patients treated with tamoxifen, particularly those displaying a decreased response, to modify the treatment accordingly. Different methods for detecting P-glycoprotein in patients with tumor drug resistance exist, including immunocytochemistry or immunohistochemistry, flow cytometry, efflux pump tests, and RT-PCR analysis [24].

\section{CONCLUSION}

In all, concomitant treatment with piperine and tamoxifen effectively prevents the development of breast cancer cells' resistance against tamoxifen, and this effect was probably seen due to the inhibition of P-glycoprotein expression.

\section{CONFLICTS OF INTEREST}

All authors have none to declare.

\section{REFERENCES}

1. Global Burden of Disease Cancer Collaboration, Fitzmaurice C, Allen C, Barber RM, Barregard L, Bhutta ZA, et al. Global, regional, and national cancer incidence, mortality, years of life lost, years lived with disability, and disability-adjusted life-years for 32 cancer groups, 1990 to 2015: A systematic analysis for the global burden of disease study. JAMA Oncol 2017;3:524-48.

2. Apuri S. Neoadjuvant and adjuvant therapies for breast cancer. South Med J 2017;110:638-42.

3. Nabholtz JM, Buzdar A, Pollak M, Harwin W, Burton G, Mangalik A, et al. Anastrozole is superior to tamoxifen as first-line therapy for advanced breast cancer in postmenopausal women: Results of a North American multicenter randomized trial. Arimidex study group. J Clin Oncol 2000;18:3758-67.

4. Mouridsen H, Gershanovich M, Sun Y, Pérez-Carrión R, Boni C, Monnier A, et al. Superior efficacy of letrozole versus tamoxifen as first-line therapy for postmenopausal women with advanced breast cancer: Results of a Phase III study of the international letrozole breast cancer group. J Clin Oncol 2001;19:2596-606.

5. Eckford PD, Sharom FJ. ABC efflux pump-based resistance to chemotherapy drugs. Chem Rev 2009;109:2989-3011.

6. Harmsen S, Meijerman I, Febus CL, Maas-Bakker RF, Beijnen JH, Schellens JH, et al. PXR-mediated induction of P-glycoprotein by anticancer drugs in a human colon adenocarcinoma-derived cell line. Cancer Chemother Pharmacol 2010;66:765-71.

7. Amin ML. P-glycoprotein inhibition for optimal drug delivery. Drug Target Insights 2013;7:27-34.

8. Bansal T, Jaggi M, Khar RK, Talegaonkar S. Emerging significance of flavonoids as P-glycoprotein inhibitors in cancer chemotherapy. J Pharm Pharm Sci 2009;12:46-78.

9. Abdallah HM, Al-Abd AM, El-Dine RS, El-Halawany AM. P-glycoprotein inhibitors of natural origin as potential tumor chemosensitizers: A review. J Adv Res 2015;6:45-62.

10. Aher S, Biradar S, Gopu CL, Paradkar A. Novel pepper extract for enhanced P-glycoprotein inhibition. J Pharm Pharmacol 2009;61:1179-86.

11. Singh A, Duggal S. Piperine-review of advances in pharmacology. Int J Pharm Sci Nanotech 2009;2:615-20.

12. Louisa M, Sugiarti L, Kurniawan SV, Wanandi SI. Curcumin increases anti-cancer activity of tamoxifen in $\mathrm{MCF}-7$ breast cancer cells through the suppression of MDR1 mRNA expression. Adv Sci Lett 2017;23:6838-40.

13. Livak KJ, Schmittgen TD. Analysis of relative gene expression data using real-time quantitative PCR and the 2(-delta delta C(T)) method. Methods 2001;25:402-8.

14. Yang K, Wu J, Li X. Recent advances in the research of P-glycoprotein inhibitors. Biosci Trends 2008;2:137-46.

15. Lykkesfeldt AE, Madsen MW, Briand P. Altered expression of estrogen-regulated genes in a tamoxifen-resistant and ICI 164,384 and ICI 182,780 sensitive human breast cancer cell line, MCF-7/TAMR-1. Cancer Res 1994;54:1587-95.

16. Lin JH. Drug-drug interaction mediated by inhibition and induction of 
P-glycoprotein. Adv Drug Deliv Rev 2003;55:53-81.

17. Purushothaman A, Nandhakumar E, Sachdanandam P. Anticancer effect of shemamruthaa (a phytochemical formulation) on 7, 12-dimethybenz (a) anthracene induced mammary carcinoma in rats. Asian J Pharm Clin Res 2012;5:101-7.

18. Tapadiya G, Metku M, Deokate U, Khadabadi S, Saboo S, Sahu K. Quantitatives estimation of piperine from pharmaceutical dosage form by HPTLC. Asian J Pharm Clin Res 2009;2:47-50.

19. Patel S, Vyas N. Validated spectrofluorimetric method for estimation of piperine in an ayurvedic formulation. Asian J Pharm Clin Res 2012;5:231-3.

20. Callaghan R, Higgins CF. Interaction of tamoxifen with the multidrug resistance P-glycoprotein. Br J Cancer 1995;71:294-9.

21. Li S, Lei Y, Jia Y, Li N, Wink M, Ma Y, et al. Piperine, a piperidine alkaloid from Piper nigrum re-sensitizes P-gp, MRP1 and BCRP dependent multidrug resistant cancer cells. Phytomedicine 2011;19:83-7.

22. Bhardwaj RK, Glaeser H, Becquemont L, Klotz U, Gupta SK, Fromm MF, et al. Piperine, a major constituent of black pepper, inhibits human P-glycoprotein and CYP3A4. J Pharmacol Exp Ther 2002;302:645-50.

23. Han Y, Chin Tan TM, Lim LY. In vitro and in vivo evaluation of the effects of piperine on P-gp function and expression. Toxicol Appl Pharmacol 2008:230:283-9.

24. Beck WT, Grogan TM, Willman CL, Cordon-Cardo C, Parham DM, Kuttesch JF, et al. Methods to detect P-glycoprotein-associated multidrug resistance in patients' tumors: Consensus recommendations. Cancer Res 1996;56:3010-20. 